\title{
Development, implementation, and evaluation of a competency-based didactic and simulation-focused boot camp for incoming urology residents: Report of the first three years
}

Yuding Wang, $\mathrm{MD}^{1}$; Jen Hoogenes, $\mathrm{MS}, \mathrm{MSc}, \mathrm{PhD}^{1}$; Roderick Clark, $\mathrm{MD}^{2}$; Nathan $\mathrm{C}$. Wong, $\mathrm{MD}^{1,3}$; Udi Blankstein, $\mathrm{MD}^{1}$; Harkanwal Randhawa, $\mathrm{MD}^{1}$; Catherine Lovatt, $\mathrm{MD}^{1}$; Kevin Kim, MSc, MD/PhD[c] $]^{1,4}$; Noah Stern, MD²; Jeffrey Law,MD²; Samir Sami, MD²; Michael Uy, MD ${ }^{1}$; Courtney Moore, MSc, MBChB[c] $]^{1,4,5}$; Bobby Shayegan, MD ${ }^{1,6}$; Anil Kapoor, MEng, MD ${ }^{1,6}$; Shahid Lambe, MD ${ }^{1,6}$; Timothy Davies, MD ${ }^{1,6}$; Sumit Dave, MSc, MCh, MD ${ }^{2}$; Alp Sener, MD, $\mathrm{PhD}^{2}$; Edward D. Matsumoto, MEd, MD ${ }^{1,6}$

${ }^{1}$ Department of Surgery, Division of Urology, McMaster University, Hamilton, ON, Canada; ${ }^{2}$ Department of Surgery, Division of Urology, Western University, London, ON, Canada; ${ }^{3}$ Department of Urology, Memorial Sloan Kettering Cancer Center, New York, NY, United States; ${ }^{4}$ Department of Health Research Methods, Evidence, and Impact, McMaster University, ON, Canada; ${ }^{5}$ University of Dundee Medical School, Dundee, Scotland, United Kingdon; ${ }^{6}$ St. Joseph's Healthcare Hamilton, McMaster Institute of Urology, Hamilton, ON, Canada

Acknowledgement: The authors would like to thank: McMaster Surgical Associates

Staff of CMAS: Magdalena Gilles and Marie Fairgrieve; Lauren Douglas, McMaster Urology Residency Program Coordinator; Kimberly Nitz, Western University Urology Residency Program Coordinator; Karl Storz Endoscope Canada Ltd., Mississauga, ON, Canada, for the donation of demonstration cystoscopes, ureteroscopes and resectoscopes used in the practical components of the course; St. Joseph's Healthcare Hamilton; Ali Al-Hashimi for technical and website design assistance.

Support: This study was supported by the McMaster University Surgical Associates Grant.

Cite as: Wang Y, Hoogenes J, Clark R, et al. Development, implementation, and evaluation of a competency-based didactic and simulation-focused boot camp for incoming urology residents: Report of the first three years. Can Urol Assoc J 2020 September 28; Epub ahead of print. http://dx.doi.org/10.5489/cuaj.6679

Published online September 28, 2020 


\begin{abstract}
Introduction: The Royal College of Physicians and Surgeons of Canada's Competence by Design (CBD) initiative presents curricula challenges to ensure residents gain proficiency while progressing through training. To prepare first-year urology residents (R1s), we developed, implemented, and evaluated a didactic and simulation-focused boot camp to implement the CBD curriculum. We report our experiences and findings of the first three years.

Methods: Urology residents from two Canadian universities participated in the two-day boot camp at the beginning of residency. Eleven didactic and six simulation sessions allowed for instruction and deliberate practice with feedback. Pre-and post-course multiple-choice questionnaires (MCQs) and an objective structured clinical exam (OSCE) evaluated knowledge and skills uptake. For initial program evaluation, three R2s served as historical controls in year 1. Results: Nineteen residents completed boot camp. The mean age was $26.4( \pm 2.8)$ and 13 were male. Participants markedly improved on the pre- and post-MCQs (year 1: 62\% and 91\%; year 2: 55\% and 89\%; year 3: 58\% and 86\%, respectively). Participants scored marginally higher than the controls on four of the six OSCE stations. OSCE scores remained $>88 \%$ over the three cohorts. All participants reported higher confidence levels post-boot camp and felt it was excellent preparation for residency.
\end{abstract}

Conclusions: During its first three years, our urology boot camp has demonstrated high feasibility and utility. Knowledge and technical skills uptake were established via MCQ and OSCE results, with participants' scores near or above those of R2 controls. This boot camp will remain in our CBD curriculum and can provide a framework for other urology residency programs.

\title{
Introduction
}

Residency programs worldwide are adopting competency-based medical education (CBME) curricula with specialty-specific objectives that must be met by residents in order to progress through training and become certified to practice independently. In Canada, this is mandated by the Royal College of Physicians and Surgeons of Canada's (RCPSC) CanMEDS framework, the most recent of which was published in 2015. ${ }^{1}$ The RCPSC's new initiative, Competence by Design (CBD), is a CBME model of resident training focused on demonstrating knowledge, skills, and performance via the achievement of specific observable milestones aligned with entrustable professional activities (EPAs) along a continuum, effectively modifying the traditional time-spent model. ${ }^{1,2}$ This competence continuum explicitly describes the expectations during the stages of training, including the transition from medical school to residency. ${ }^{3}$ 
When entering residency, the CBD model's focus is on the orientation and assessment of new trainees and is tailored to the needs of each specific program ${ }^{3}$; however, there are no available guidelines on how to bridge this gap and adequately prepare incoming residents. In 2016, in anticipation of the CBD rollout, some Canadian universities implemented a Surgical Foundations ${ }^{4}$-based boot camp that runs annually during the first two weeks of surgical residency to provide a basic orientation to surgical practice. As these boot camps are not specialty-specific, first-year residents (R1s) may be vulnerable to stress and anxiety related to a real or perceived lack of knowledge and skills as they enter their respective programs. ${ }^{5-7}$ In 2018 , the RCPSC expanded upon their specialty-specific Transition to Discipline (TTD) requirements. For urology, this includes required and recommended clinical training (e.g., clinic, inpatient and emergency services, rounds, after-hours coverage) and other training (e.g., early clinical and technical skills training, simulation training) ${ }^{8}$ Despite these requirements, there were no specific guidelines for providing this TTD orientation. Surgical specialty-specific boot camps have been shown to be effective in preparing learners for residency, especially with respect to objective skills assessment and subjective reports of increased trainee confidence. ${ }^{9-12}$ Since urology was going to be one of the first specialties in Canada to adopt the CBD curriculum, we preemptively developed, implemented, and evaluated a urology-specific boot camp curriculum for incoming residents as a strategy to implement CBD. Here, we describe our experience and findings over the first three years (2017-2019) of the McMaster University/Western University Urology Boot Camp, which, to our knowledge, is the first to be implemented in Canada.

\section{Methods}

\section{Curriculum design}

In 2016, our team of urology residents and staff set out to develop an intensive two-day curriculum that incorporates didactic and simulation-based learning objectives, culminating in a multi-station Objective Structured Clinical Examination (OSCE) and multiple-choice questionnaire (MCQ) for evaluation. We incorporated a stepwise backward curriculum design model whereby we began with specific learning objectives and then selected the content and materials used to meet these objectives. This approach guided our content outline, development of instructional procedures (didactic and practical), and creation of our evaluation criteria. Using a modified Delphi approach via two iterations, we conducted a survey of senior residents, fellows, and staff from two urology residency programs to identify topics R1s should know prior to starting their first week of residency and for their first night of call. The final list of topics was reviewed by the curriculum committee and the two urology program directors until a consensus was reached. Topics were then divided into didactic and practical components and courseware was developed to address each topic. We ensured that the didactic and simulation-based sessions were ordered sequentially to allow participants to build upon each session to meet the learning objectives for each topic. Additionally, we secured the resources required to implement the boot 
camp, including the lecture hall, the simulation centre and simulators required for the practical sessions and the OSCE, and facilitators and staff for each part of the boot camp.

The first boot camp was held in July of 2017 immediately following Surgical Foundations and prior to beginning clinical duties. The course was designed to be short to avoid any service disruptions. The boot camp was held at the same time in July of 2018 and 2019.

\section{Course content and procedures}

Course content mapping was completed to match urological core competencies and EPAs as defined by the RCPSC Urology Specialty Training Requirements. ${ }^{13}$ Material for each topic was sourced from Campbell-Walsh Urology $\left(11^{\text {th }}\right.$ Edition $),{ }^{14}$ Canadian Urological Association and American Urological Association guidelines and best practice statements, and relevant peerreviewed journal articles. Participants were provided with all references used for each topic. A total of 11 didactic and 6 practical sessions were delivered (didactic sessions were conducted in the morning and practical sessions in the afternoon). Participants received detailed daily agendas, with a description of each topic's learning objectives. Each didactic session focused on one topic and included example patient cases. The morning didactic sessions were held in a lecture hall and averaged approximately one hour, depending on the complexity of the topic. The afternoon practical sessions in the simulation lab lasted approximately 2 hours and 30 minutes and included didactic components related to the applications for the simulated tasks followed by demonstration and hands-on practice.

A detailed curriculum map with each topic's corresponding foundations and core EPA(s) is shown in Table 1.As the boot camp was an introductory course for R1s, it was not feasible to teach and evaluate each of the milestones delineated in the corresponding EPAs, as this is completed during residency in practice. Instead, the EPAs were used as a guide for the selection of introductory topics and simulation-based procedures. The TTD \#1, "Assessing patients with a urological presentation", served as an initial guide for introductory topics in the boot camp curriculum. ${ }^{13}$

Practical sessions were held in the Centre for Minimal Access Surgery (CMAS) simulation lab at St. Joseph's Healthcare Hamilton. Low and high-fidelity simulators were used, including validated commercial trainers and models developed specifically for the boot camp (Figures 1-4). Each simulation session had pre-defined learning objectives that each participant must meet during the post-boot camp OSCE. During the hands-on sessions, participants were able to practice while receiving additional instruction and feedback from senior urology residents and staff urologists.

All course content and past schedules are published on our boot camp website (www.urologybootcamp.com), which is available for all participants prior to, during, and after the course. The website includes all didactic and practical content, as well as procedural videos (e.g., suprapubic catheter insertion, scope assembly, flexible cystoscopy) and links to references, guidelines, and websites of urological organizations. The Hamilton Integrated Research Ethics 
Board has granted continuing ethics approval for the boot camp. Informed consent was obtained and all participants were assigned an identification number to be used during the entirety of the boot camp. Confidentiality was maintained throughout.

\section{Evaluation metrics}

\section{Pre-course assessment}

A 31-question MCQ test was developed for pre-course baseline knowledge evaluation. The questions were derived from the course content references and covered general urological knowledge. Participants also completed a 16-item survey using a 4-point Likert scale designed to elicit baseline confidence levels (Appendix). Demographic information and previous urological surgical education experience (including simulation), as well as previous urological experience (e.g., rotations, participation in procedures) was also obtained. These assessments were conducted on the first day prior to the start of boot camp.

\section{Post-course assessment}

Participants completed a 62-question MCQ that included the questions on the baseline MCQ and additional questions related to course content covered during the boot camp. The 31 questions on the pre-course questionnaire were randomly dispersed throughout the 62-question MCQ to control for order and recall bias. The 31 questions from the pre- and post-course MCQs were compared, while the new boot camp-specific questions on the post-course MCQ were scored separately for evaluation purposes only. A 6-station OSCE was conducted at the end of the second day and included: scope assembly; flexible cystoscopy; patient positioning; gaining patient consent for ureteroscopy; management of gross hematuria; and suprapubic catheter placement. Assessment was mapped to key objectives from each topic taught, and participants answered multiple questions related to a simulated case presentation prior to completing the specific station's technical skills-related task. The OSCE was evaluated by senior urology residents and staff urologists. Participants completed an exit questionnaire that repeated the baseline confidence survey and elicited qualitative feedback on the course. A Likert scale-based survey served as a formal course evaluation, followed by a semi-structured oral debriefing session with the boot camp instructors and facilitators to elicit suggestions for improvements, additions, and/or changes to course material. All evaluation metrics were identical over the three years. Post-course assessments were completed at the end of the second day prior to the debriefing session.

In the first year, three second-year residents (R2s) completed the post-course assessment to serve as historical controls. The R2s completed the identical MCQ and OSCE as the boot camp participants, and the results were compared to aid in determining the initial utility and success of the boot camp and whether the content was comprehensive. The R2s were also asked to provide feedback on the evaluation metrics. 


\section{Results}

A total of $19 \mathrm{R} 1 \mathrm{~s}$ participated in the first three years of the boot camp (average of 6 per year). The mean age of participants was $26.3( \pm 2.4), 13$ were male, and participants came from 10 different medical schools (8 Canadian and 2 international).

The pre-and post-course MCQ results for each year are shown in Table 2, while OSCE results by year by station are displayed in Table 3. An increased level of knowledge was demonstrated based on participants' mean MCQ percentages for all years, with the pre-course ranging from $55.2 \%$ to $61.8 \%$ and post-course ranging from $86.3 \%$ to $91 \%$. There was little variation across years for mean OSCE station scores, with the lowest being gross hematuria (82\%) and the highest was suprapubic catheter insertion (98.5\%). In 2017, the R2 historical controls scored $69 \%$ on the post-course MCQ and scored marginally lower than participants in all years on three OSCE stations. Mean self-reported levels of confidence for the 16-item 4-point Likert scale questionnaire are displayed in Table 4. Evidence of improved confidence post-boot camp was demonstrated by the combined mean scores for all years showing an increase from 1.8/4 at baseline to $2.8 / 4$ after the course.

Regarding general feedback, $92 \%$ of participants strongly agreed that the boot camp met their learning objectives and prepared them well for their first rotation and call, while $90 \%$ strongly agreed that the boot camp added to their educational experience and was an excellent preparation for residency. Additionally, 93\% strongly agreed that their confidence related to urological topics and procedures covered in the course had improved prior to boot camp. During group debriefing, the majority felt that the topics covered were adequate, but they expressed wanting additional case-based discussions. When asked if participants would be open to increasing the number of trainees per course (i.e., by integrating more than two urology programs), the consensus was that its current small size was seen as a strength, as it allows for more one-on-one teaching.

\section{Discussion}

An intensive, two-day competency-based and simulation-focused boot camp for incoming urology residents has been successfully developed, implemented, and evaluated for the past three years (2017-2019) at McMaster University, in conjunction with Western University. The course was developed out of a need for a urology-specific boot camp that would prepare incoming R1s for residency while aligning with the new CBD initiative. With the RCPSC's specialty-specific TTD requirements, our boot camp aimed to bridge the gap between medical school and surgical residency, while incorporating didactic and practical teaching with objective evaluation measures. Our boot camp has provided R1s with urology-specific education that immediately follows the Surgical Foundations boot camp at the beginning of residency, prior to any clinical rotation and/or call. As evidenced by the objective results and subjective feedback of participants over the previous three years, our boot camp has proven to be highly successful in preparing R1s 
for residency. This success has led to the incorporation of this boot camp into our formal urology residency curriculum.

The boot camp curriculum content was based off of the RCPSC Urology Specialty Training Requirements' core competencies, ${ }^{13}$ and the use of simulation allowed participants to learn and practice procedures, many of which corresponded with the didactic topics. The validated simulators (Figures 1-4) equipped trainees with high-fidelity models and scopes to prepare them to perform procedures during practice. The CMAS lab provided participants with an excellent training facility, where senior residents and staff urologists were able to train participants, provide feedback, and allow for repetitive practice on the simulators. Incorporating simulation into the practical sessions of the boot camp was critical to participants being exposed to urology procedures. Exposure to simulation early in residency has been shown to significantly improve trainees' competence and confidence to perform in the clinical setting. ${ }^{15-17}$ Specifically for this course, our team created an ultrasound-compatible suprapubic catheterization simulator (Figure 3), which has since been validated. ${ }^{18}$ As urologic technology advances,,${ }^{19}$ it will be important to continue to introduce new simulators and technologies into the boot camp curriculum to ensure residents receive the most comprehensive and up-to-date simulation training.

The formal evaluation using the pre- and post-course MCQs and the OSCE proved highly valuable in assessing the boot camp. The curriculum content and order of delivery did not change over the three years except for the addition of the robotic surgery module in 2019, which was added based on participant comments. Although participants were not formally tested on robotic content, its inclusion received positive feedback. As the pre- and post-course evaluation metrics remained identical, our team was able to uniformly assess the impact of the boot camp on participants' didactic and procedural knowledge, as well as subjective measures such as confidence levels. There was little variation across all years for the MCQ scores, including when comparing the 31 pre-course MCQs to the post-course answers to the same 31 questions (Table 2). There was a notable increase in pre- and post-course MCQ scores, evidentiary of successful delivery and uptake of didactic content (Table 2). Participants received high OSCE scores, with no failing marks, and little variation in scores was observed between years (Table 3). As it is not feasible or meaningful to run a pre-course OSCE, we could not compare baseline versus courseacquired technical skills for the procedures taught.

The inclusion of the three R2 historical controls in the first year assisted in evaluating the curriculum content by comparing participants' MCQ and OSCE results to those of residents who had just completed their first year. The R2s scored $22 \%$ lower than the same year's post-course MCQ (Table 2). This may have been the result of recall bias, as the boot camp participants had been immersed in the course content that comprised the MCQs, and also had the opportunity to study the content. However, there was little variation in the OSCE scores between the R1s and $\mathrm{R} 2 \mathrm{~s}$ (Table 3). The exception is the R2s' higher mean score of $95.7 \%$ for the flexible cystoscopy 
station, which is likely due to volume of exposure to cystoscopy as a R1. We recognize that the R2s were not true controls in the sense of experimental design; however, we felt it was important to include them in the first year as a means to evaluate whether the boot camp curriculum held some validity in that it covered learning objectives and procedural tasks that would be important for R1s to be exposed to prior to residency. Importantly, the R2s' assessment results cannot demonstrate external validity and generalizability of the findings.

As a whole, participants' self-reported levels of confidence increased by close to 1 Likert scale point (on a 4-point scale) from baseline, indicating that, post-boot camp, the majority of participants are at least somewhat to very confident on the items in the survey (Appendix; results in Table 4). Increased confidence was also captured by the majority of participants via the exit surveys. These findings are similar to recent reports of new surgical boot camps for incoming residents, ${ }^{9,10}$ which provides further evidence of the utility of boot camps for improving trainees' confidence prior to entering residency.

The boot camp course has proven to be effective on many levels since its inception; however, it is not without limitations. It is important to consider that R1s enter residency with various educational and experiential backgrounds; therefore, the baseline MCQ serves to assess the knowledge base of all participants relative to boot camp topics. This has been effective, as we have not had any significant score outliers, nor have there been any for the OSCEs. Secondly, we have had multiple residents serve as instructors and evaluators, which is unavoidable as residents graduate. To mitigate this, we have ensured comprehensive and consistent training and handover to newly involved residents. We have also maintained the same boot camp urology staff directors and course coordinator, and several residents, which has ensured the continuity of the program. Additionally, aside from informal communication with past participants, we have not had a formal plan in place to evaluate the short and long-term effects of the course. We now have a means to assess participants at 3,6, and 12-month follow-up periods via an online survey, which will include some MCQs and confidence surveys, while also eliciting qualitative feedback. This will be initiated after the 2020 boot camp. We also intend to add more robotic training, as well as a focus on non-technical skills, such as debriefing, to create a more comprehensive curriculum.

With respect to portability of the boot camp, we intend to evaluate the logistics of holding the course at another university in July of 2020. We recognize the limitation that programs may not have the tools required to implement this course. Successful transfer to other sites will require maintaining the methodology and ensuring that facilities, equipment, and staff/residents are available and trained for their respective roles. The initial up-front cost of developing and implementing this boot camp was funded through a grant and required a one-time purchase of the Bristol TURP Trainer (Figure 1), the Uro-Scopic Trainer (Figure 2), as well as the materials used for the construction of multiple suprapubic catheter models (Figure 3) to ensure there are enough for demonstration, practice, and the OSCE. We are able to use the CMAS simulation centre and its simulators at no cost (CMAS website: https://www.cmas.ca/). An industry 
representative afforded us the use of their training scopes at no cost. We welcome inquiries from interested programs with hopes of widely disseminating the course to other institutions.

Our website (www.urologybootcamp.com) is also available to assist programs with developing and implementing the boot camp. Evaluation of this boot camp at other centres, as well as the potential to compare OSCE results between urology programs, will allow us and other programs to determine what is required to ensure the success of the course in the future, especially as the field evolves and training objectives change.

\section{Conclusions}

During its first three years, our urology boot camp has demonstrated high feasibility and utility. Participants in all years exhibited knowledge and technical skills uptake via MCQ and OSCE results, and confidence levels increased substantially. The boot camp has become part of our CBD-based urology residency curriculum and can be adapted for implementation in other urology programs. 


\section{References}

1. Frank JR, Snell L, Sherbino J, eds. CanMEDS 2015 Physician Competency Framework. Ottawa: Royal College of Physicians and Surgeons of Canada; 2015.

2. Van Melle E, Frank J, Brzeznia S, Gorman L. Competency by Design - Residency Education: A Framework for Program Evaluation. DRAFT. Ottawa, Ontario, Canada: Royal College of Physicians and Surgeons of Canada; 2017.

3. Royal College of Physicians and Surgeons of Canada. CanMEDS 2015 CBD Competence Continuum http://www.royalcollege.ca/rcsite/documents/cbd/cbd-competencecontinuum-diagram-legal-e.pdf. Accessed March 7, 2020.

4. Royal College of Physicians and Surgeons of Canada. Objectives of Surgical Foundations Training 2010 (Editorial revision - June 2016, version 1.3) http://www.royalcollege.ca/rcsite/documents/ibd/surgical-foundations-otr-e . Accessed March 7, 2020.

5. Dabrow S, Russell S, Ackley K, Anderson E, Fabri PJ. Combating the stress of residency: one school's approach. Acad Med. 2006;81(5):436-9.

6. Radcliffe $\mathrm{C}$, Lester $\mathrm{H}$. Perceived stress during undergraduate medical training: a qualitative study. Med Educ. 2003;37(1):32-8.

7. Lyss-Lerman P, Teherani A, Aagaard E, et al. What training is needed in the fourth year of medical school? Views of residency program directors.;Acad Med. 2009;84(7):823-9

8. Royal College of Physicians and Surgeons of Canada. Urology Training Experiences 2018 (version 1.0) http://www.royalcollege.ca/rcsite/documents/ibd/urology-rte-trainingexperiences-e.pdf. Accessed March 7, 2020.

9. Bevilacqua LA, Simon J, Rutigliano D, et al. Surgical boot camp for fourth-year medical students: Impact on objective skills and subjective confidence. Surgery. 2020;167: 298301.

10. Nakazato T, Callahan Z, Kuchta K, et al. A 1-day simulation-based boot camp for incoming general surgery residents improves confidence and technical skills. Surgery. 2019;166: 572-579.

11. Neylan CJ, Nelson EF, Dumon KR et al. Medical school surgical boot camps: a systematic review. J Surg Educ. 2017;74: 384-389.

12. Young M, Kailavasan M, Taylor J et al. The success and evolution of a urological "boot camp" for newly appointed UK urology registrars: incorporating simulation, nontechnical skills and assessment. J Surg Educ. 2019; 76:1425-1432.

13. Royal College of Physicians and Surgeons of Canada. Specialty Training Requirements in Urology. 2011 (Editorial revision January 2014, version 1.1). http://www.royalcollege.ca/rcsite/documents/ibd/urology str e.pdf Accessed March 7, 2020.

14. Wein AJ, Kavoussi LR, Partin AW, Peters CA (Eds.). (2012). Campbell-Walsh Urology $11^{\text {th }}$ Ed. Philadelphia: WB Saunders.

15. Ahmed K, Patel S, Aydin A et al. European Association of Urology Section of Urolithiasis (EULIS) Consensus Statement on Simulation, Training, and Assessment in Urolithiasis. Eur Urol Focus. 2018; 4(4):614-620. 
16. Viswaroop SB1, Gopalakrishnan G, Kandasami SV. Role of transurethral resection of the prostate simulators for training in transurethral surgery. Curr Opin Urol. 2015;25(2):1537.

17. Kumar A, Smith R, Patel VR. Current status of robotic simulators in acquisition of robotic surgical skills. Curr Opin Urol. 2015; 25(2):168-74.

18. Wang Y, Blankstein U, Hoogenes J, et al. Development and initial validation of a lowcost ultrasound- compatible suprapubic catheter insertion training simulator. Can Urol Assoc J. 2018; 12(6Suppl2).

19. Bernstein DE, Bernstein BS. Urological technology: where will we be in 20 years' time? Ther Adv Urol. 2018;10(8):235-242.

20. Urology Specialty Committee. EPA Guide: Urology. Ottawa: Royal College of Physicians and Surgeons of Canada; 2017. 


\section{Figures and Tables}

Fig. 1. Bristol transurethral resection of the prostate trainer. From manufacturer (https://limbsandthings.com/uk/). A complete training system for the transurethral resection of the prostate (TURP) using monopolar and bipolar electrosurgery. This model was developed in conjunction with the Institute of Urology, Southmead Hospital, Bristol, UK. Skills: Fluid management; insertion, manipulation, and removal of instruments; identification of anatomical landmarks and tissue types; resection techniques within lifelike spatial constraints; evacuation of chips and bladder flushing.
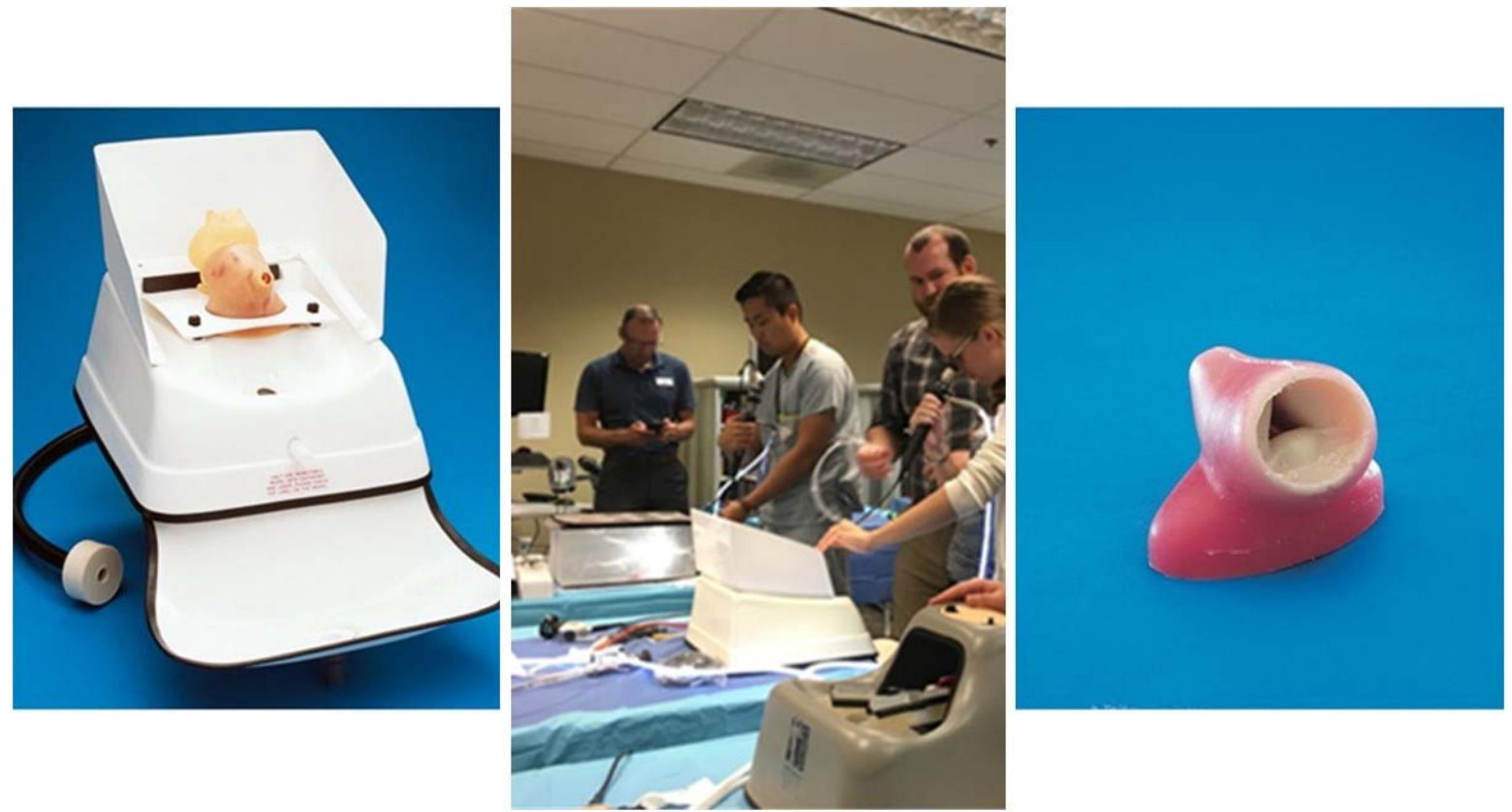
Fig. 2. Uro-scopic trainer. From manufacturer (https://limbsandthings.com/uk/):

A versatile model that provides for a range of urological endoscopic techniques and procedures to be acquired in line with a trainees clinical progression. Skills: Fluid management; insertion, manipulation and removal of instruments; examination of the urethra (urethroscopy); examination of the bladder (cystoscopy); examination of the ureters using rigid or flexible instruments (ureteroscopy); stent and guidewire insertion; lithotripsy; stone retrieval.

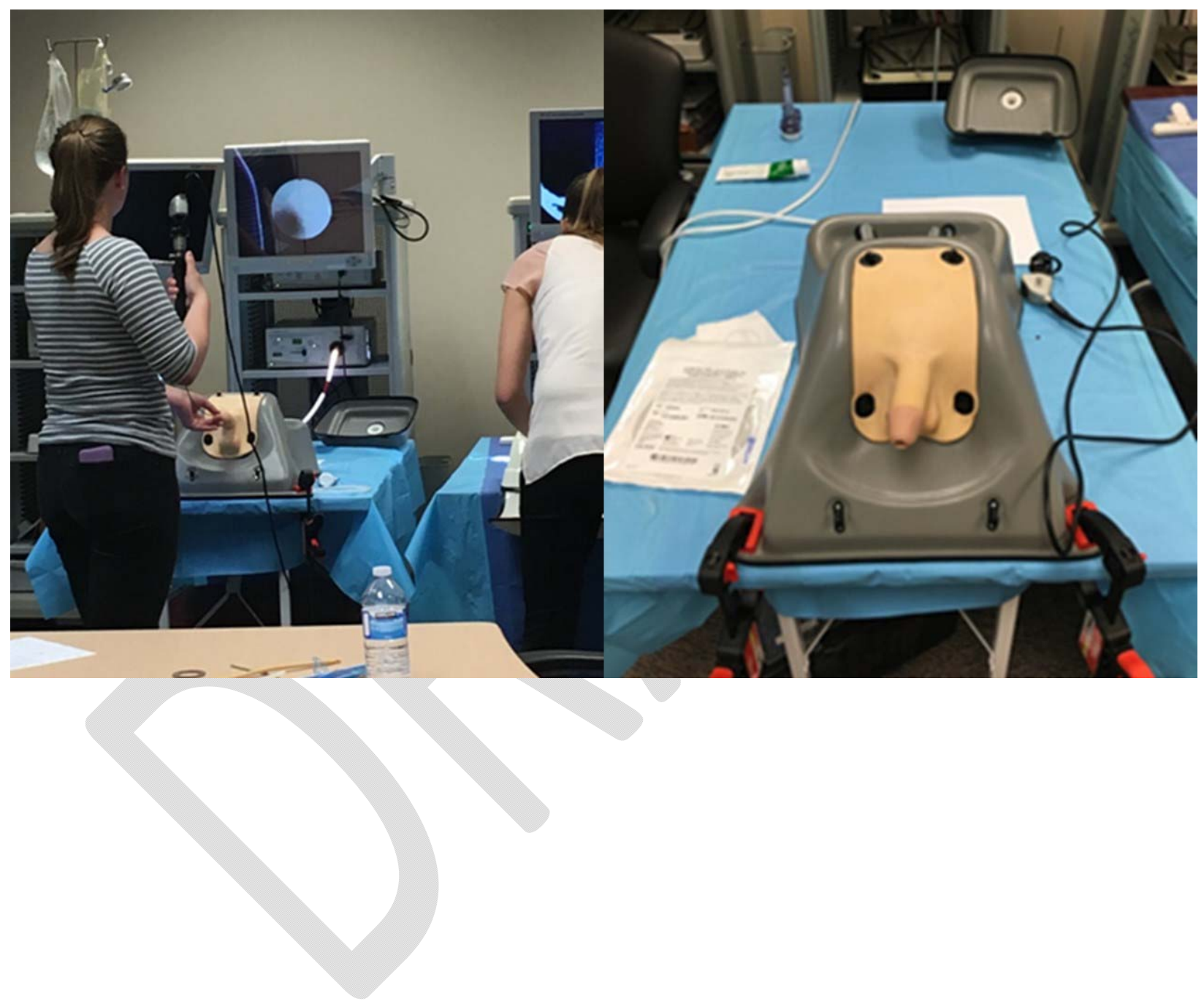


Fig. 3. Suprapubic catheter insertion simulator - ultrasound-compatible. This model was created by our team for the urology boot camp and has since been validated. It has been used every year of the boot camp for practice and the OSCE. Multiple models are available for use throughout the boot camp. The model is comprised of the following: bladder $-3 \mathrm{~L}$ normal saline irrigation bag under pressure via tourniquet; rectum - $100 \mathrm{~mL}$ normal saline bag injected with red food coloring; skin layer - silicone skin model without layers purchased from a medical/surgical simulation company; subcutaneous tissue layer - ultrasound compatible agar gelatin in a $100 \mathrm{~mm}$ x $100 \mathrm{~mm}$ mold, which is $15 \mathrm{~mm}$ thick; housing - a shoebox-sized plastic box with a snap on plastic lid to provide stability (a square portion of the lid is cut out to simulate the suprapubic catheterization site); suprapubic catheter introducer kit - obtained from medical supplier; ultrasound gel - obtained from medical supplier; drape - reusable sterile draping to cover the box, with a hole cut into the drape to expose the simulated suprapubic catheterization site. The total cost of this model is \$48 CAD.

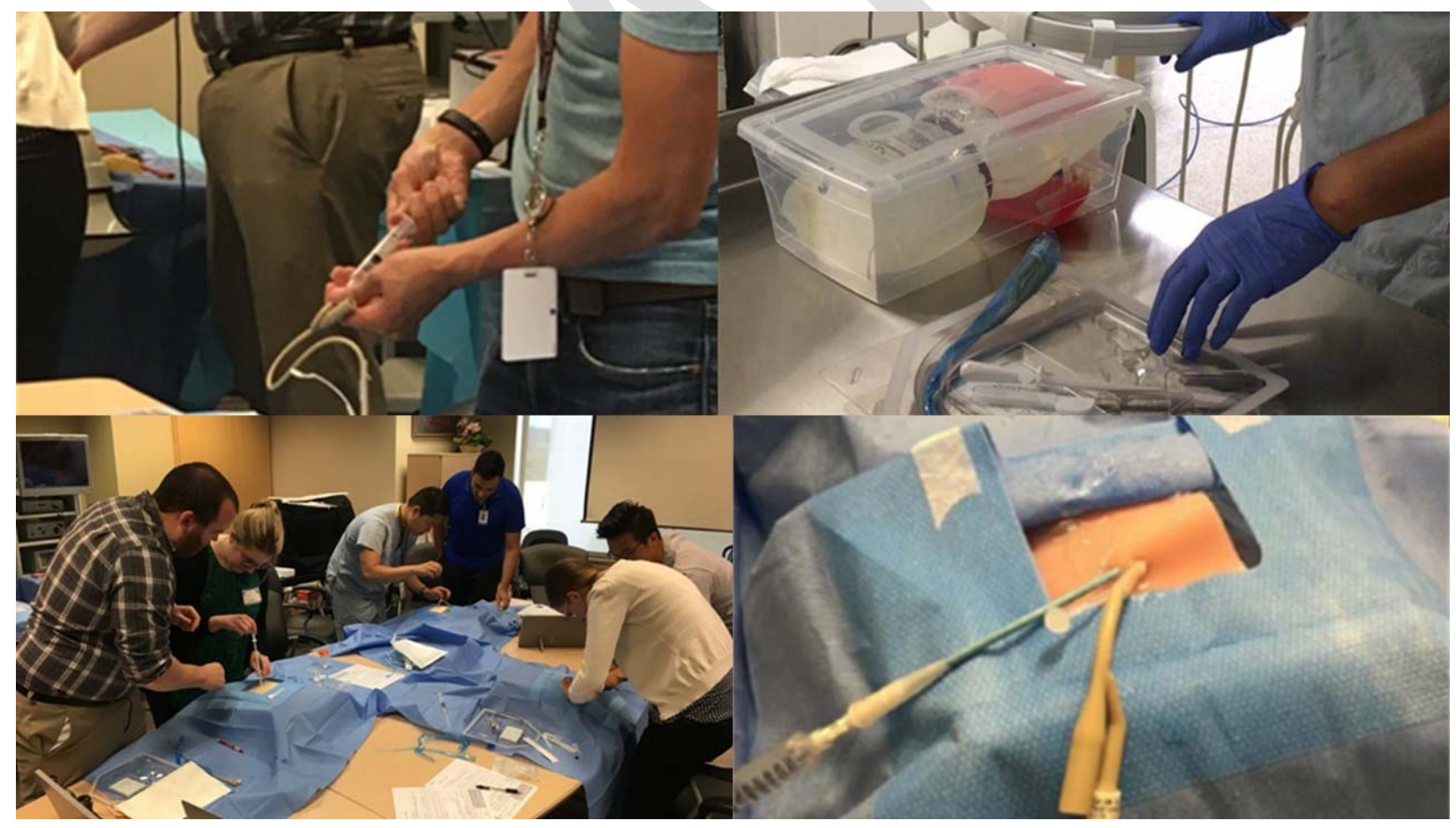


Fig. 4. Mimic ${ }^{\circledR}$ da Vinci Robotic Trainer (dV-Trainer ${ }^{\circledR}$, shown from the CMAS lab (www.cmas.ca). From manufacturer's website (https://mimicsimulation.com/dv-trainer/): "The dV-Trainer ${ }^{\circledR}$ is Mimic's full-size, fully adjustable simulator that can be paired with procedure-specific modules to provide a complete robotic surgical training solution. The $\mathrm{dV}$ Trainer $^{\circledR}$ features a stereoscope, master grips, foot pedals, and force effects that closely emulate the da Vinci ${ }^{\circledR}$ Surgeon's Console, while providing cost-effective and accessible training outside of the OR, when and where it's most convenient."

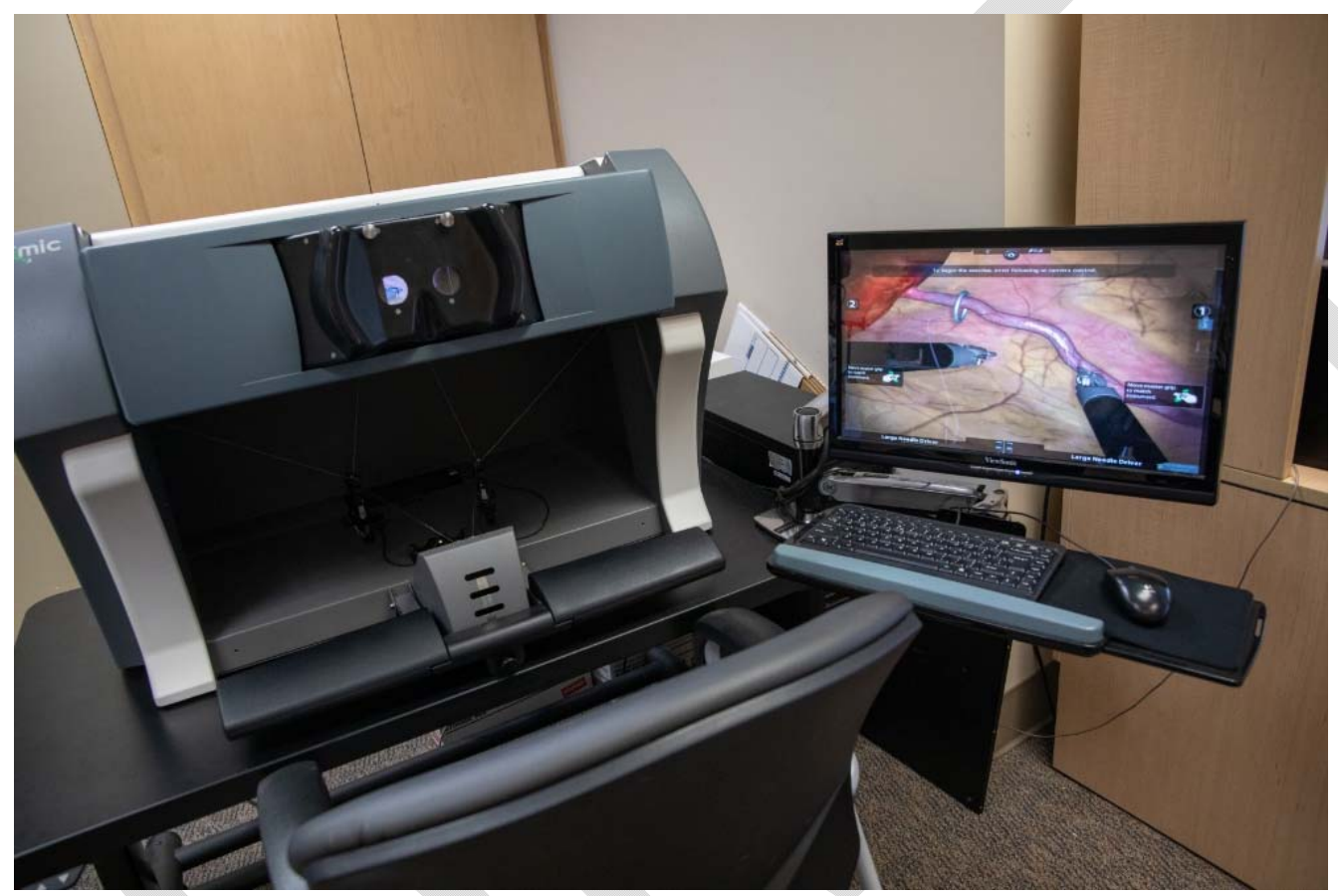




\begin{tabular}{|c|c|}
\hline Topic and EPA(s) ${ }^{* *}$ & Objectives \\
\hline & Patient cases and literature ${ }^{*}$ \\
\hline \multicolumn{2}{|l|}{ Day 1} \\
\hline $\begin{array}{l}\text { Lecture 1: Gross hematuria } \\
\text { Foundations EPA } 1 \\
\text { Foundations EPA } 4 \\
\text { Core EPA } 1\end{array}$ & 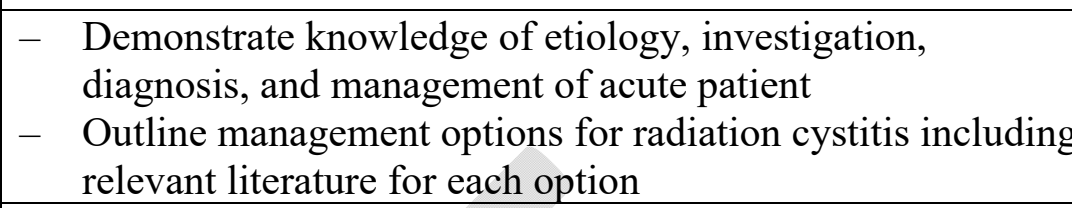 \\
\hline $\begin{array}{l}\text { Lecture 2: Testicular torsion } \\
\text { Foundations EPA } 3 \\
\text { Core EPA } 1\end{array}$ & $\begin{array}{ll}- & \text { Demonstrate knowledge of etiology, investigation, } \\
& \text { diagnosis, and management of acute patient } \\
- & \text { Analyze physical exam findings } \\
- & \text { Outline surgical approach and expected outcomes }\end{array}$ \\
\hline $\begin{array}{l}\text { Lecture 3: Septic stone } \\
\text { Foundations EPA } 1 \\
\text { Foundations EPA } 2 \\
\text { Foundations EPA } 4 \\
\text { Core EPA } 1\end{array}$ & $\begin{array}{l}\text { - Demonstrate knowledge of etiology, investigation, } \\
\text { diagnosis, and management of acute patient } \\
\text { - Describe management approach for stent vs. nephrectomy } \\
\text { tube } \\
\text { - Outline general management of septic patient }\end{array}$ \\
\hline $\begin{array}{l}\text { Lecture 4: Post-obstructive } \\
\text { diuresis } \\
\text { Foundations EPA } 1 \\
\text { Foundations EPA } 2 \\
\end{array}$ & $\begin{array}{l}\text { Demonstrate knowledge of etiology, investigation, } \\
\text { diagnosis, and management of acute patient }\end{array}$ \\
\hline $\begin{array}{l}\text { Practical 1: Difficult Foley, } \\
\text { bedside cystoscopy, } \\
\text { suprapubic catheter insertion } \\
\text { Foundations EPA } 1 \\
\text { Foundations EPA } 5 \\
\text { Foundations EPA } 6 \\
\text { Core EPA } 3\end{array}$ & $\begin{array}{l}\text { - Outline etiology and management of difficult catherization } \\
\text { - Define key components of bedside cystoscopy } \\
\text { - Demonstrate flexible cystoscopy } \\
\text { - Identify strategies for difficult Foley catheterization } \\
\text { - } \text { Identify key anatomic landmarks } \\
\text { - Demonstrate appropriate instrument handling, tissue } \\
\text { handling, and safe technique } \\
\text { - Perform suprapubic catheter insertion technique }\end{array}$ \\
\hline $\begin{array}{l}\text { Practical 2: Patient } \\
\text { positioning } \\
\text { Procedural-based EPAs }\end{array}$ & $\begin{array}{l}\text { Describe and demonstrate common patient positioning in } \\
\text { urological surgery } \\
\text { - Describe common complications associated with incorrect } \\
\text { patient positioning }\end{array}$ \\
\hline $\begin{array}{l}\text { Practical 3: Orientation to } \\
\text { robotic surgery } \\
\text { Simulation-based EPAs }\end{array}$ & $\begin{array}{l}\text { - } \\
\text { - } \\
\text { Rescribe the fundamentals of robotic surgery } \\
\text { reality desktop robotic simulator }\end{array}$ \\
\hline \multicolumn{2}{|l|}{ Day 2} \\
\hline $\begin{array}{l}\text { Lecture 1: Trauma } \\
\text { (renal/ureteric/ } \\
\text { urethral/bladder/scrotal) } \\
\text { Foundations EPA } 3\end{array}$ & $\begin{array}{l}\text { Demonstrate knowledge of etiology, investigation, } \\
\text { diagnosis, and management of acute trauma patient }\end{array}$ \\
\hline
\end{tabular}




\begin{tabular}{|c|c|}
\hline Core EPA 1 & $\begin{array}{l}\text { - Outline management options for each stage of trauma } \\
\text { (renal, ureteric, bladder, urethral, scrotal) including relevant } \\
\text { literature for each option }\end{array}$ \\
\hline $\begin{array}{l}\text { Lecture 2: Priaprism } \\
\text { Foundations EPA } 3 \\
\text { Core EPA } 1\end{array}$ & 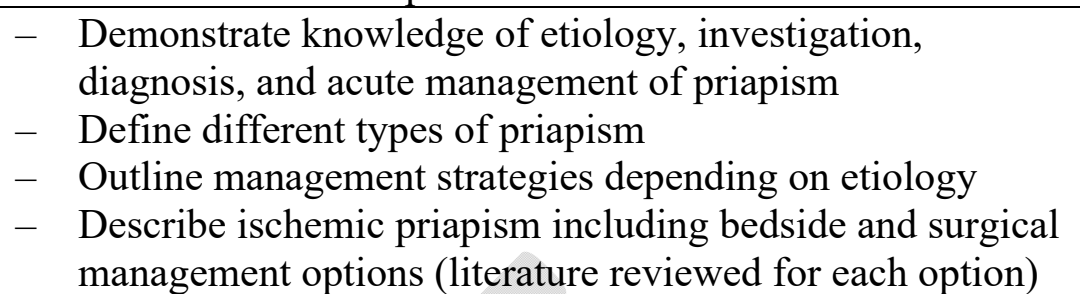 \\
\hline $\begin{array}{l}\text { Lecture 3: Infection of GU } \\
\text { tract - a primer (focus on } \\
\text { emphysematous } \\
\text { cystitis/nephritis); brief } \\
\text { discussion on Fournier's } \\
\text { Foundations EPA } 3 \\
\text { Foundations EPA } 4 \\
\text { Core EPA } 1\end{array}$ & $\begin{array}{l}\text { Demonstrate knowledge of etiology, investigation, } \\
\text { diagnosis, and acute management of GU infections } \\
\text { requiring hospitalization } \\
\text { - Demonstrate knowledge of etiology, investigation, } \\
\text { diagnosis, and acute management of patients with } \\
\text { Fournier's }\end{array}$ \\
\hline $\begin{array}{l}\text { Practical 1: TUR simulator } \\
\text { Foundations EPA } 5 \\
\text { Foundations EPA } 6 \\
\text { Core EPA } 5 \\
\text { Core EPA } 6\end{array}$ & $\begin{array}{ll}- & \text { Identify components of rigid cystoscope } \\
\text { - } & \text { Demonstrate knowledge of basic prostate anatomy and } \\
\text { management of BPH } \\
\text { - } \\
\text { - } \\
\text { - } \text { Identify knowledge of TUR simulator and practice } \\
\text { Demonstrate appropriate tissue handling, instrument } \\
\text { handling, and safe technique }\end{array}$ \\
\hline $\begin{array}{l}\text { Practical 2: Ureteroscopy } \\
\text { simulator } \\
\text { Core EPA } 8 \\
\text { Core EPA } 9\end{array}$ & $\begin{array}{l}\text { - Outline etiology and management of upper tract disease } \\
\text { (focus on stones) } \\
-\quad \text { Define key components of flexible ureteroscope } \\
-\quad \text { Perform simulated flexible ureteroscopy and define } \\
\text { strategies for stone management } \\
-\quad \text { Identify key landmarks } \\
-\quad \text { Demonstrate appropriate tissue handling, instrument } \\
\text { handling, and safe technique }\end{array}$ \\
\hline
\end{tabular}

*Patient cases and literature: For each lecture and practical, example patient cases are discussed, including the following components: 1) physical examination/labs/imaging; 2) initial management; 3) differential diagnosis; 4) management - clinical/surgical/medical; 5) additional information related to each case/topic. Literature references are listed for each session. The full boot camp curriculum can be found at: www.urologybootcamp.com. ${ }^{* *}$ EPA: entrustable professional activity ${ }^{8,13,20}$ (note: some EPAs overlap between topics): Foundations EPA 1: assessing and managing patients with a difficult catheterization in an urgent setting; foundations EPA 2: recognizing and managing urosepsis in patients with urinary obstruction; foundations EPA 3: assessing and managing patients with acute scrotal/perineal pain; foundations EPA 4: assessing and establishing a management plan for patients with common non-emergent urological presentations; foundations EPA 5: performing rigid cystoscopy with examination in an elective setting; foundations EPA 6: performing flexible cystoscopy with examination in an 
elective setting. Core EPA 1: performing an initial consultation, and developing a plan for investigation or management, for patients presenting to the emergency department; core EPA 3: performing an intraoperative consultation for a simple scenario; core EPA 5: performing transurethral resection of bladder tumors; core EPA 6: performing transurethral resection of prostate; core EPA 8: performing rigid ureteroscopy and lithotripsy of the upper urinary tract; core EPA 9: performing retrograde flexible ureteroscopy/nephroscopy and lithotripsy of the upper urinary tract.

\begin{tabular}{|c|c|c|c|}
\hline Year & Pre 31-item & Post 31-item* & Post 62-item \\
\hline $\begin{array}{l}2017 \\
(n=6)\end{array}$ & $61.8(11.1)$ & $89.7(6.6)$ & $91(6.7)$ \\
\hline $\begin{array}{l}\text { R2 controls }{ }^{\dagger} \\
(n=3)\end{array}$ & & & $69(6.6)$ \\
\hline $\begin{array}{l}2018 \\
(n=6)\end{array}$ & $55.2(10.3)$ & $91.4(7.2)$ & $88.5(8.6)$ \\
\hline $\begin{array}{l}2019 \\
(n=7)\end{array}$ & $57.7(11.8)$ & $88.3(6.5)$ & $86.3(4.2)$ \\
\hline Mean $\%$ all years & 58.2 & 89.8 & 88.6 \\
\hline
\end{tabular}

*Mean percentage correct on the 31 items used on the pre-course MCQ, for comparison. †Post-course 62-item MCQ mean percentage result from the $3 \mathrm{R} 2 \mathrm{~s}$ who served as historical controls during the first year of boot camp. MCQ: multiple-choice questionnaire; SD: standard deviation. 


\begin{tabular}{|l|c|c|c|c|c|}
\hline \multicolumn{2}{|l|}{ Table 3. Results of each OSCE station by year, mean \% (SD) } \\
\hline OSCE station & $\mathbf{2 0 1 7}$ & $\begin{array}{c}\mathbf{2 0 1 7} \mathbf{R 2} \\
\text { controls }\end{array}$ & $\mathbf{2 0 1 8}$ & $\mathbf{2 0 1 9}$ & $\begin{array}{c}\text { Mean \% } \\
\text { for all } \\
\text { years* }\end{array}$ \\
\hline $\begin{array}{l}\text { Flexible } \\
\text { cystoscopy }\end{array}$ & $82.8(10.8)$ & $95.7(1.5)$ & $89(9.0)$ & $87(7.6)$ & 86.3 \\
\hline $\begin{array}{l}\text { Gross } \\
\text { hematuria }\end{array}$ & $78.5(10.5)$ & $76.7(7.4)$ & $78.7(6.2)$ & $88.7(2.7)$ & 82 \\
\hline $\begin{array}{l}\text { Informed } \\
\text { consent for } \\
\text { ureteroscopy }\end{array}$ & $98.5(1.6)$ & $87.7(12.5)$ & $98.4(0.7)$ & $89.1(10.3)$ & 94.4 \\
\hline $\begin{array}{l}\text { Patient } \\
\text { positioning }\end{array}$ & $92.2(5.2)$ & $91.7(14.4)$ & $92.5(9.1)$ & $97.4(6.8)$ & 94 \\
\hline $\begin{array}{l}\text { Scope } \\
\text { assembly }\end{array}$ & $77.5(14.9)$ & $79.3(2.1)$ & $85(7.6)$ & $87.1(9.5$ & 83.2 \\
\hline $\begin{array}{l}\text { Suprapubic } \\
\text { catheter } \\
\text { insertion }\end{array}$ & $99.5(1.2)$ & $98(3.5)$ & $99.7(1.3)$ & $96.4(7.2)$ & 98.5 \\
\hline
\end{tabular}

"R2 controls excluded. OSCE: objective structured clinical exam; SD: standard deviation.

\begin{tabular}{|l|c|c|}
\hline \multicolumn{3}{|l|}{ Table 4: Participants' self-reported level of confidence levels* } \\
pre- and post-boot camp \\
\hline Year & Pre-course & Post-course \\
\hline 2017 & 1.9 & 2.6 \\
\hline 2018 & 1.8 & 2.9 \\
\hline 2019 & 1.8 & 2.8 \\
\hline Mean score/4 & 1.8 & 2.8 \\
\hline
\end{tabular}

*Based on 16 items rated on a 4-point Likert scale: $1=$ not confident at all; $2=\mathrm{a}$ little confident; $3=$ somewhat confident; $4=$ =very confident. 